\title{
artigo
}

Oliveria, Z.N.O.; Simplício, I.O.B.; Ribeiro, A.D.; Araújo, C.S.S.; Coutinho, B.S.; Oliveira, L.G.; Nascimento, R.C.M.; Anjos, D.M.G.;

Análise microbiológicas das maçanetas da clínica médica de um hospital público do interior da Amazônia

\section{Análise microbiológicas das maçanetas da clínica médica de um hospital público do interior da Amazônia}

\author{
Microbiological analysis of the torches of the medical clinic of a public hospital in the interior of the Amazon \\ Análisis microbiológico de las antorchas de la clínica médica de un hospital público en el interior del Amazonas
}

\begin{abstract}
RESUMO
Objetivo: Avaliar as condições microbiológicas das maçanetas internas e externas das portas da unidade de clínica médica de um Hospital Público no interior da Amazônia, Município de Santarém, Oeste do Pará, Brasil. Método: Pesquisa exploratório-descritiva, quantitativa, realizado através de amostras da superfície de maçanetas das portas da clínica médica de um Hospital em Santarém-Pará. A análise microbiológica, foi realizada no agitador para dessorção das bactérias e a suspensão foi semeada por esgotamento. Resultados: Das 84 maçanetas, 26,2\% apresentaram resultado microbiológico positivo, sendo encontrada em todos os casos a bactéria Staphylococcus sp. Quanto o material de cobertura, 25\% das maçanetas estavam comprometido, sendo que, dentre os casos positivos na análise microbiológica, 18,2\% das maçanetas estavam com a superfície prejudicada. Conclusão: Apesar do número de amostras positivas serem relativamente pequenos, é importante destacar ações voltada para a higienização dos fômites hospitalares, dado que estes podem funcionar como reservatórios de microrganismos patogênicos. DESCRITORES: Análise Microbiológica; Infecção Hospitalar; Bactéria.
\end{abstract}

\section{ABSTRACT}

Objective: To value the microbiological conditions of the internal and external door handles of the doors of the medical clinic unit of a Public Hospital in the interior of the Amazon, Santarém Municipality, West of Pará, Brazil. Method: Exploratory-descriptive, quantitative research, carried out through surface samples and door handles of the medical clinic of a hospital in Santarém-Pará. Microbiological analysis was performed not the agitator for bacteria desorction and the suspension was soed by exhaustion. Results: Of the 84 doorknobs, 26,2\%presentedpositive microbiological results, and Staphylococcus sp bacteria were found in all cases. As for the cover material, $25 \%$ of the doorknobs were compromised, and among the positive cases in the microbiological analysis, $18,2 \%$ of the door knobs had the affected surface. Conclusion: Although the number of positive samples is relatively small, it is important to highlight actions aimed at the hygiene of hospital fomites, since these can function as reservoirs of pathogenic microorganisms. DESCRIPTORS: Microbiological Analysis, Cross Infection, Bacteria.

\section{RESUMEN}

Objetivo: Valorar las condiciones microbiológicas de las manijas de las puertas internas y externas de las puertas de la unidad clínica médica de un Hospital Público en el interior del Amazonas, Municipio de Santarém, Oeste de Pará, Brasil. Método: Investigación exploratoria-descriptiva, cuantitativa, realizada a través de muestras superficiales y manijas de puertas de la clínica médica de un hospital en Santarém-Pará. Se realizó un análisis microbiológico no el agitador para la desorción de bacterias y la suspensión fue sosed por agotamiento. Resultados: De los 84 pomos de las puertas, el 26,2\%presentóresultados microbiológicos positivos, y se encontraron bacterias Staphylococcus sp en todos los casos. En cuanto al material de cubierta, el $25 \%$ de los pomos de las puertas se vieron comprometidos, y entre los casos positivos en el análisis microbiológico, el 18,2\% de las perillas de las puertas tenían la superficie afectada. Conclusión: Aunque el número de muestras positivas es relativamente pequeño, es importante destacar las acciones encaminadas a la higiene de los fámites hospitalarios, ya que pueden funcionar como reservorios de microorganismos patógenos.

DESCRIPTORES: Análisis Microbiológico, Infección Hospitalaria, Bacterias.

RECEBIDO EM: 15/01/2021 APROVADO EM: 05/02/2021

\section{Zaline de Nazare Oliveira de Oliveira}

Enfermeira, Universidade do Estado do Pará.

ORCID: 0000-0001-7083-4973 
Irinéia de Oliveira Bacelar Simplício

Enfermeira, Mestre em Bioengenharia pela UNICASTELO.

ORCID: 0000-0001-8271-9569

\section{Andreza Dantas Ribeiro}

Enfermeira, Mestranda em Biociências pela Universidade Federal do Oeste do Pará.

ORCID: 0000-0002-0017-8488

Carla Suellem Sousa Araújo

Enfermeira, Mestranda em Sociedade, Ambiente e Qualidade de Vida pela Universidade Federal do Oeste do Pará.

ORCID: 0000-0001-6844-4781

\section{Brenda dos Santos Coutinho}

Enfermeira, Mestranda em Biociências pela Universidade Federal do Oeste do Pará.

ORCID: 0000-0001-5449-6003

\section{Leticia Gomes de Oliveira}

Enfermeira, Mestranda em Epidemiologia e Vigilância em Saúde pelo Instituto Evandro Chagas.

ORCID: 0000-0002-8830-728X

\section{Raiane Cristina Mourão do Nascimento}

Enfermeira, Universidade do Estado do Pará.

ORCID: 0000-0002-7306-9258

\section{Dara Marcela Gama dos Anjos}

Enfermeira, Coordenadora da Estratégia da Família São Jorge.

ORCID: 0000-0003-3205-7522

\section{INTRODUÇÃO}

A s Infecções Relacionadas à Assistência à Saúde (IRAS) são aquelas adquiridas após a admissão do paciente e se manifestam durante a internação ou após a alta quando relacionada com procedimentos hospitalares ou internação ${ }^{(1)}$. Representam um dos mais importantes problemas de saúde pública no mundo, sendo classificada como evento adverso ao tratamento do paciente e causa do aumento da morbimortalidade, ocasionando repercussões no que diz respeito ao tempo de hospitalização, ao custo do tratamento, à segurança e à qualidade dos serviços de saúde $e^{(2)}$.

De um modo geral, as IRAS estão associadas o perfil de gravidade dos pacientes, uso de imunossupressores, realização de procedimentos invasivos, período prolongado de internação, uso indiscriminado de antimicrobianos e ao próprio ambiente hospitalar, que favorece a seleção natural de microrganismos ${ }^{(3)}$.

Milhões de pacientes são afetados pelas

\section{As Infecções}

Relacionadasà

Assistência à Saúde

(IRAS) são aquelas

adquiridas após a

admissão do paciente e

se manifestam durante

a internação ou após a

alta quando relacionada

com procedimentos

hospitalares ou

internação
IRAS a cada ano no mundo, causando um aumento no índice de morbimortalidade e prejuízos financeiros para os sistemas de saúde. Estima-se que a cada 100 pacientes hospitalizados, sete em países desenvolvidos e 10 em países em desenvolvimento irão adquirir pelo menos uma IRAS ${ }^{(1)}$. Ressalta-se que, de acordo com dados do European Centre for Disease Prevention and Control (2016), cerca de $20 \%$ a $30 \%$ das IRAS são consideradas preveníveis por meio dos programas de controle e higiene intensivos ${ }^{(4)}$.

Pesquisas que abordam o ambiente de disseminação de bactérias hospitalares no Brasil são poucas e utilizam bases de dados, raramente brasileiras. Não há evidencias concretas de que as contaminações cruzadas através de superfícies contaminadas favoreçam as infecções hospitalares. As superfícies apresentam baixo risco de transmissão direta de infecção, porém contribuem para a contaminação cruzada secundária, por meio de contatos dos profissionais de saúde e de equipamentos ou instrumentos com tais superfícies, que poderão ser contamina- 


\section{artigo}

Oliveria, Z.N.O.; Simplício, I.O.B.; Ribeiro, A.D.; Araújo, C.S.S.; Coutinho, B.S.; Oliveira, L.G.; Nascimento, R.C.M.; Anjos, D.M.G.;

Análise microbiológicas das maçanetas da clínica médica de um hospital público do interior da Amazônia

das e, posteriormente, acabar contaminando os pacientes e outras locais manipulados com frequência ${ }^{5,6)}$.

Fatores como a capacidade de os microrganismos sobreviverem em superfícies inanimadas e a falta de limpeza específica dessas superfícies, o que dificultam a remoção dos patógenos, reforçam os indícios de que os ambientes hospitalares representam fontes de colonização e de disseminação de patógenos ${ }^{(7)}$.

$\mathrm{O}$ ambiente hospitalar, torna-se contaminado e, consequentemente, as superfícies inanimadas e os equipamentos são potenciais reservatórios de bactérias, em especial, as resistentes aos antimicrobianos $^{(8)}$. A partir disso, ressaltam -se os fômites como um importante desafio para o controle e prevenção de IRAS, pois estes podem servir como reservatórios secundários e acarretar contaminação cruzada. Em vista disso, as maçanetas das portas dos setores hospitalares constituem um fômite de intensa manipulação, o que eleva a possibilidade de contaminação ${ }^{(9)}$.

Dessa forma, manter o ambiente biologicamente seguro é papel também dos profissionais da saúde. As mãos dos profissionais são reconhecidamente as vias mais comuns de transmissão de patógenos, entre o paciente e o ambiente, e essas estão em contato direto com o paciente na realização dos procedimentos ${ }^{(10)}$.

Logo, este estudo teve o seguinte questionamento: "Qual as condições microbiológicas das maçanetas das portas da unidade de clínica médica de um Hospital no Município de Santarém, Pará?". O estudo buscou avaliar as condições microbiológicas das maçanetas internas e externas das portas da unidade de clínica médica de um Hospital Público no interior da Amazônia, Município de Santarém, Oeste do Pará, Brasil.

\section{MÉTODO}

Caracteriza-se como uma pesquisa exploratório-descritiva de abordagem quantitativa e qualitativa. A pesquisa foi desenvolvida no período de maio a agosto de 2018 em um Hospital Público de média e alta complexidade do Interior da Amazônia, no Município de Santarém, Oeste do Pará, Brasil.

O estudo foi realizado através de coletas de amostras da superfície das maçanetas internas e externas das portas da clínica médica da referida instituição hospitalar, nos dias 22 de maio, 09 e 19 de agosto, visto que a aquisição dos insumos foi efetiva-

Tabela 1 - Distribuição dos locais de procedência das maçanetas da clínica médica por resultado de teste, Santarém, Pará, Brasil, 2018.

\begin{tabular}{|c|c|c|c|c|c|c|}
\hline \multirow{3}{*}{ LOCAL } & \multirow{3}{*}{$\begin{array}{l}\text { N DE AMOSTRA } \\
\text { ESTUDADA }\end{array}$} & \multirow{3}{*}{$\%$} & \multicolumn{4}{|c|}{ RESULTADOS DOS TESTES } \\
\hline & & & \multicolumn{2}{|c|}{ POSITIVO } & \multicolumn{2}{|c|}{ NEGATIVO } \\
\hline & & & $\mathbf{N}$ & $\%$ & $\mathbf{N}$ & $\%$ \\
\hline Enfermarias & 18 & 21,4 & 5 & 27,7 & 13 & 72,3 \\
\hline Banheiro das enfermarias & 18 & 21,4 & 4 & 22,2 & 14 & 77,8 \\
\hline $\begin{array}{l}\text { Posto de enfermagem e } \\
\text { banheiro }\end{array}$ & 4 & 4,7 & 4 & 100,0 & - & - \\
\hline Porta do elevador & 4 & 4,7 & 3 & 75,5 & 1 & 25,5 \\
\hline Arsenal & 2 & 2,3 & 1 & 50,0 & 1 & 50,0 \\
\hline $\begin{array}{l}\text { Isolamento e banheiro do } \\
\text { isolamento }\end{array}$ & 6 & 7,1 & 1 & 16,7 & 5 & 83,3 \\
\hline Equipamento médico & 2 & 2,3 & 1 & 50,0 & 1 & 50,0 \\
\hline $\begin{array}{l}\text { Alojamento residente médico } \\
\text { e banheiro }\end{array}$ & 4 & 4,7 & - & - & 4 & 100,0 \\
\hline $\begin{array}{l}\text { Alojamento multiprofissional } \\
\text { e banheiro }\end{array}$ & 4 & 4,7 & - & - & 4 & 100,0 \\
\hline
\end{tabular}

da em função da logística necessária para a manutenção da qualidade do produto e o tempo de validade com duração média de 90 dias.

Foi utilizada o KIT SRK, o qual contém o swab estéril, sendo que este foi manipulado, obedecendo as orientações do fabricante. Inicialmente, o swab foi umedecido em solução tampão com neutralizante (que acompanha o swab), comprimindo-o contra as paredes do frasco de diluente, para remover o excesso de líquido. $\mathrm{O}$ algodão do swab foi friccionado três vezes em movimento de zigue-zague. Após isso, os microrganismos coletados foram transferidos para o tubo contendo $10 \mathrm{ml}$ de solução tampão com agentes neutralizantes, para inativar possíveis quantidades residuais de agentes sanificantes.

Os tubos foram levados por um minuto para o agitador Mixtron (Toptronix) para dessorção das bactérias. A suspensão foi semeada por esgotamento, com o próprio swab, em placas de Petri às semeaduras diretas e incubadas à temperatura ambiente por no mínimo três dias. A semeadura foi realizada nos meios de cultura Agar McConkey e Agar Sangue. A avaliação microbiológica foi realizada no Laboratório Santos, Santarém-Pará.

Para a análise dos dados foi utilizado à técnica de análise descritiva, no software Microsoft Excel ${ }^{\circ}$ 2013. O estudo foi aprovado pelo comitê de ética em pesquisa (CEP) da Universidade do Estado do Pará Campus-XII conforme parecer 3.148.072, em conformidade com a resolução 466/12.

\section{RESULTADOS}

As amostras constituíram-se de 84 maçanetas, sendo 42 das enfermarias com seus respectivos banheiros; 6 banheiros corredor; 4 do alojamento da residência médica com seu banheiro; 2 da sala de equipamento médico; 2 da farmácia satélite; 2 da copa; 4 do alojamento multiprofissional; 2 do posto de enfermagem; 4 da porta que oferece acesso a escada; $4 \mathrm{da}$ porta que dar acesso ao hall do elevador; 2 da porta que dar acesso ao hall de serviço, sendo que este contém um arsenal, um 


$\begin{array}{lcccccc}\text { Banheiro do corredor } & 4 & 4,7 & 1 & 25,0 & 3 & 75,0 \\ \text { Farmácia } & 2 & 2,3 & - & - & 2 & 100,0 \\ \text { Copa } & 2 & 2,3 & - & - & 2 & 100,0 \\ \text { Porta do hall de serviço } & 6 & 7,1 & 1 & 16,7 & 5 & 83,3 \\ \text { Porta de acesso à escada } & 4 & 4,7 & 1 & 25,0 & 3 & 75,0 \\ \text { Solário } & 4 & 4,7 & - & - & 4 & 100,0 \\ \text { Total } & 84 & 100 & 22 & 26,2 & 62 & 73,8 \\ \text { Fonte: Dados da pesquisa, 2018. } & & & & & & \end{array}$

Tabela 2-Distribuição dos locais com positividade microbiológica por área, Santarém, Pará, Brasil, 2018.

\begin{tabular}{lcccc} 
& \multicolumn{2}{c}{ INTERNA } & \multicolumn{2}{c}{ EXTERNA } \\
& N & $\%$ & N & $\%$ \\
Enfermarias & 2 & 9,0 & 3 & 13,6 \\
Banheiro enfermaria & 1 & 4,5 & 3 & 13,6 \\
Posto de enfermagem e banheiro & 2 & 9,0 & 2 & 9,0 \\
Banheiro isolamento & - & - & 1 & 4,5 \\
Banheiro corredor & 1 & 4,5 & - & - \\
Equipamento médico & 1 & 4,5 & - & - \\
Porta do elevador & 1 & 4,5 & 2 & 9,0 \\
Porta de acesso à escada & - & - & 1 & 4,5 \\
Porta do hall de serviço & 1 & 4,5 & - & - \\
Arsenal & 1 & 4,5 & - & - \\
Total & 10 & 45,4 & 12 & 54,5 \\
Fonte: Dados da pesquisa, 2018. & & & &
\end{tabular}

Gráfico 1. Maçanetas da clínica médica com achado microbiológico positivo e negativo em relação ao comprometimento do material de cobertura de superfície, Santarém, Pará, Brasil, 2018.

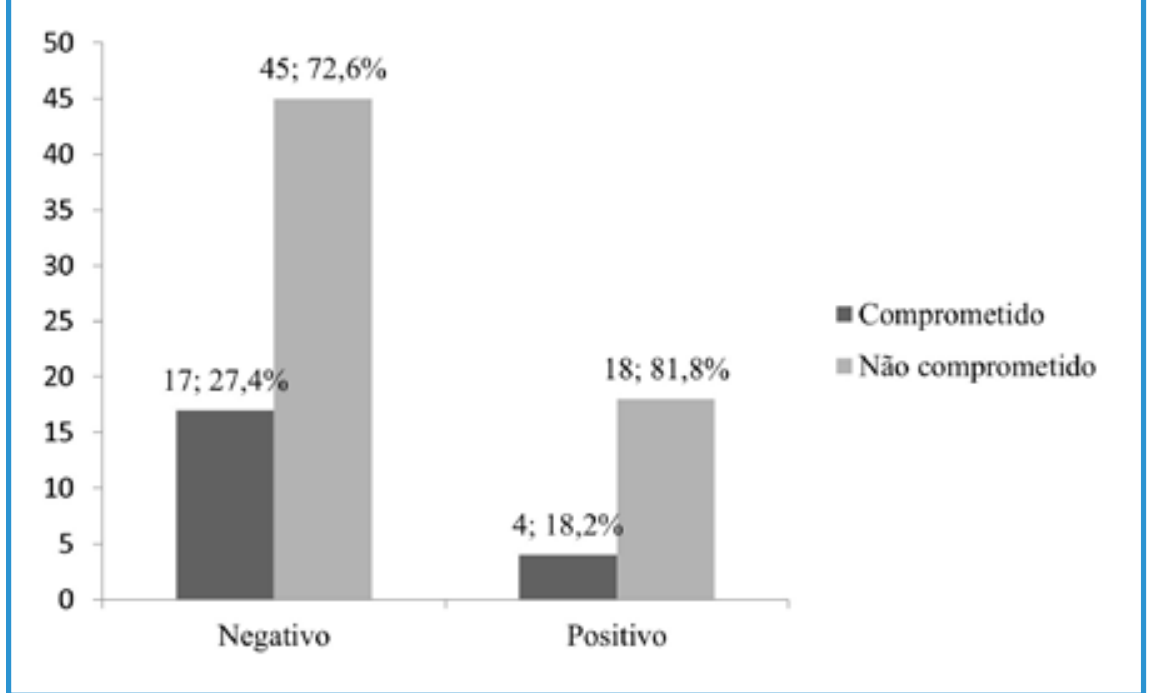

Fonte: Dados da pesquisa, 2018. expurgo e uma rouparia, contabilizando mais 6 maçanetas; e 4 do solário.

Das 84 maçanetas analisadas, 26,2\% ${ }^{(22)}$ apresentaram resultado microbiológico positivo, sendo encontrada em todos os casos a bactéria Staphylococcus sp. Foi possível observar que a maior frequência estava nos banheiros das enfermarias em $100 \%$, seguido das enfermarias com $27,7 \%$ (Tabela 1$)$.

Das $22(26,2 \%)$ maçanetas que tiveram resultado positivo, as enfermarias e banheiro das enfermarias apresentaram maior positividade nas maçanetas externas com $13,6 \%{ }^{(3)}$ cada, já as maçanetas internas que obtiveram mais resultados positivos foi a das enfermarias e posto de enfermagem com seu respectivo banheiro, positivando $9,1 \%{ }^{(2)}$ cada. Além disso, as demais maçanetas internas dos banheiros das enfermarias, banheiro do corredor, porta do hall do elevador, arsenal, equipamento médico e porta do hall de serviço ambas apresentaram $4,5 \%$ de positividade, enquanto que das externas apenas o banheiro de isolamento e a porta de acesso à escada apresentaram 4,5\% (Tabela 2).

Cabe destacar que durante a coleta foi visualizado que $25 \%{ }^{(21)}$ das maçanetas estavam com o material de cobertura comprometido, sendo que, dentre os casos positivos na análise microbiológica, $4(18,2 \%)$ das maçanetas estavam com a superfície prejudicada, tal como demonstrado no gráfico 1 .

\section{DISCUSSÃO}

Estudo sobre os principais agentes infecciosos envolvidos em infecções hospitalares, as bactérias gram-positivas, como o Staphylococcus aureus tiveram maior prevalência, tal constatação foi perceptível neste estudo ${ }^{(11)}$. Outro trabalho que corrobora com este é uma revisão da literatura ao qual o microrganismo encontrado com mais frequência nas superfícies e/ou equipamentos do ambiente hospitalar foi Staphylococcus aureus ${ }^{(7)}$.

O Staphylococcus aureus é um dos principais microrganismos que infectam indivíduos, e apesar de pertencer à microbiota, 
essa bactéria tem um grau de patogenicidade alta pois se dissemina fácil em ambiente hospitalar e possui uma associação a resistência a antibióticos ${ }^{(12)}$.

Tal prevalência de Staphylococcus aureus pode ser explicada pela presença dessa bactéria na microbiota humana e sua maior abrangência nas mãos e cavidade nasal, sendo, portanto, facilmente transportada por profissionais de saúde, além, da maior contaminação e incidência de fômites onde há maior contato por parte de profissionais da saúde, como maçanetas, torneiras, grades de camas, monitores, teclados e o que está relacionado com o fato de que superfícies muito tocadas se tornam mais contaminadas ${ }^{(13)}$.

Diversos estudos apontam as mãos de profissionais como principais fontes de disseminação e colonização de patógenos, pois muitas vezes os profissionais, após tocar em um paciente ou manipular utensílios e equipamento possivelmente contaminados, retomam a suas atividades sem realizar a higienização correta das mãos, não levando em conta a possibilidade de transferência de patógenos para outros locais de grande manipulação. Assim, outras superfícies manipuladas com regularidade se tornam grande potencial de agir dos microrganismos $^{(8)}$.

Os microrganismos, inclusive os multirresistentes estão também nas mais distintas partes de um ambiente hospitalar e que a limpeza desses ambientes em conjunto com o cuidado profissional é um importante fator para evitar a ocorrência de infecções hospitalares. Dessa forma, é imprescindível um ambiente higienizado de maneira correta somada a manutenção dos objetos hospitalares para a diminuição de microrganismos patogênicos no ambiente ${ }^{(14)}$.

Não há evidencias concretas de que as contaminações cruzadas através de superfícies contaminadas favoreçam as infecções hospitalares, mas há evidências de que os itens utilizados no ambiente hospitalar sirvam de depósitos secundários podendo carrear contaminação cruzada, ou seja, os ambientes mal higienizados devem ser considerados como fonte ${ }^{(10)}$.

Amostras microbiológicas de superfícies
Os microrganismos,

inclusive os

multirresistentes

estão também

nas mais distintas

partes de um

ambiente hospitalar

e que a limpeza

desses ambientes

em conjunto

com o cuidado

profissional é um

importante fator

para evitar a

ocorrência

de infecções

hospitalares. podem ser úteis tanto em verificar a limpeza do ambiente quanto em investigar se as superfícies hospitalares estão atuando como possíveis fontes de doenças. As superfícies ambientais próximas a pacientes, podem se tornar fontes de microrganismos epidemiologicamente importantes, devendo ser submetido às técnicas de assepsia rotineiramente, e de acordo com o protocolo do hospital, principalmente após a alta do paciente ${ }^{(15)}$.

Apesar do quantitativo de maçanetas contaminadas com algum agente patogênico no estudo terem sido relativamente pequeno (26,2\%), a adoção de boas práticas de higienização do ambiente, lavagem das mãos, cuidados no manuseio dos fômites, tais como as maçanetas são de extrema relevância para diminuição do risco de IRAS.

As instituições de saúde têm se preocupado, haja vista que seu principal objetivo é atender com melhor qualidade o paciente $^{(16)}$. A Portaria do Ministério da Saúde $n^{\circ} 2.616 / 98$, regulamenta as ações de controle de IRAS no Brasil, dentre essas ações, regulamenta-se a formação do Programa de Controle de Infecção Hospitalar (PCIH), o qual irá desenvolver ações deliberadas e sistemáticas para o controle e prevenção das infecções hospitalares ${ }^{(17)}$. Com isso, além da redução da morbidade e mortalidade, há também a diminuição de gastos de serviços públicos, devido à necessidade de meios específicos para a assistência curativa das IRAS ${ }^{(18)}$.

Para a normatização e execução do PCIH de forma correta, é formado em cada instituição hospitalar a Comissão de Controle de Infecção Hospitalar (CCIH), esta é formada por uma equipe multiprofissional, com escolaridade de nível superior, que irá realizar a vigilância epidemiológica, para estabelecer taxas de incidência e prevalência de infecções no ambiente hospitalar. E através dos resultados poderá avaliar e elaborar, medidas de controle de riscos para a ocorrência de novas infecções, e, portanto, melhorar a assistência prestada ${ }^{(19)}$.

\section{CONCLUSÃO}

Foi possível perceber que positividade 
nas análises microbiológicas foi Staphylococcus sp. envolvido em todos os casos. Isso corrobora com o que a Comissão de Controle de Infecção Hospitalar do hospital em estudo vem trabalhando com intuito de garantir segurança aos pacientes e seus colaboradores.

E apesar do número de amostras positivas serem relativamente pequenos, a atuação da CCIH deve também está voltada para a higienização dos fômites hospitalares, dado que estes podem funcionar como reservatórios de microrganismos patogênicos. Somado a isso, a educação continuada dos profissionais de saúde é indispensável para o seguimento das normas de lavagem das mãos e cuidado no manu- seio de materiais hospitalares, bem como qualquer tipo de fômite, tal como as maçanetas das portas.

Salienta-se que estudos que comparem os microrganismos presentes nos fômites hospitalares com os envolvidos nas infecções hospitalares seriam de grande valia para evidenciar o papel dos fômites como colaboradores desse problema hospitalar. Além, de acreditar que esse estudo servirá de base para a realização de novas pesquisas acerca da temática abordada, já que, percebe-se sua relação com a qualidade de vida das pessoas. Dessa maneira, esse levantamento possibilitará escolhas de estratégias e intervenções a fim de minimizar ou erradicar as IRAS. -

\section{REFERÊNCIAS}

1. Oliveira MF, et al. Infecções relacionadas à assistência à saúde sob a ótica da enfermagem em terapia intensiva adulto/Infections related to health assistance under the view of nursing in adult intensive therapy. 2019. Ciên., Cuid. e Saúde, v. 18, n. 4.

2. Araújo BT, Pereira DCR. Políticas para controle de Infecções Relacionadas à Assistência à Saúde (IRAS) no Brasil, 2017. 2018. Comuni. em Ciên. da Saúde, v. 28, n. 03/04, p. 333-342.

3. Vesco NL, et al. Infecções relacionadas à assistência à saúde e fatores associados no pós-operatório de transplante hepático. 2018. Text. \& Context.-Enfermagem, v. 27, n. 3.

4. European Centre for Disease prevention and Control. Healthcare-associated infections. 2016. Available from: https://ecdc. europa.eu/en/healthcare-associated-infections.

5. Damasceno Q. Características epidemiológicas dos microrganismos resistentes presentes em reservatórios de uma Unidade de Terapia Intensiva [dissertation]. Belo Horizonte: Escola de Enfermagem/UFMG; 104 p. 2010.

6. Oliveira HMO, Silva CPR, Lacerda RA. Políticas de controle e prevenção de infecções relacionadas à assistência à saúde no Brasil: análise conceitual. 2016. Rev. Esc. Enferm. USP, v. 50, n. 3p. 505-11.

7. Dresch $F$, et al. Contaminação de superfícies localizadas em unidades de terapia intensiva e salas de cirurgia: uma revisão sistemática da literatura. 2018. Rev. de Epidem. e Controle de Infecção, v. 8, n. 1, p. 85-91.

8. Ferreira AM, et al. Superfícies do ambiente hospitalar: um possível reservatório de micro-organismos subestimado? - Revisão Integrativa. 2013. Revista de Enfermagem UFPE, Recife, v.7, p. 4171- 4182.

9. Silva SA, Deuschle RAN, Garlet CCM. Pesquisa de Staphylococcus aureus nas maçanetas das portas dos quartos de um hospital na região Noroeste, Rio Grande do Sul. 2012. Saúde (Santa
Maria), v. 38, n. 1, p. 129-138.

10. Barros MMA. O enfermeiro na prevenção e controle de infecções relacionadas à assistência à saúde. 2016. Universitas: Ciên. da Saúde, Brasília, v. 14, n. 1, p. 15-21.

11. Leão RNQ. Microbiologia e uso racional de antimicrobianos. Unimed Belém: prevenção e controle de infecção em serviços de saúde. Belém, 2008. 445 p.

12. Silva KAB. Pesquisa de staphylococcus aureus e escherichia coli em aparelhos celulares utilizados em laboratório. 2018.

13. Oliveira F, Melo K, Aoyama E, Rodrigues G. A importância da lavagem das mãos como atenuante microbiológico aos riscos de contágio da H1N1. 2019. Rev. Brasile. Interdi. de Saúde.1(1):33-8.

14. Schneider RS, Fontana RT. A Educação em Saúde diante dos Saberes dos Trabalhadores sobre a Prevenção da Infecção Hospitalar. 2016. Vivências. v. 12, n.22, p. 16-29.

15. Amador JFS, Basso LC, Vieira SLV. Prevalência de Staphylococcus aureus em superfícies de unidade de terapia intensiva. 2018. Arqui. do Muse. Dinâm. Interdisciplinar, v. 22, n. 2, p. 1-10.

16. Dias JVM, de Oliveira LG, da Silva Moia CM, da Silva Ferreira J, Silva JHS, \& de Souza MOLS. A percepção do enfermeiro sobre auditoria de enfermagem no âmbito hospitalar. 2020. Enferm Brasil, 18(6), 737-742.

17. Portaria $N^{\circ} 2616$, de 12 demaio de 1998. Programa de Controle de Infecção Hospitalar. 1998. Disponível em: http://bvsms.saude. gov.br/bvs/saudelegis/gm/1998/prt2616_12_05_1998.html. Acesso em: 5 de setembro de 2018.

18. Venturioso, FF; Delgadillo, J; Farias, MS; Andrade, EX. O papel educador do enfermeiro no controle da infecção hospitalar enquanto membro da CCIH. 2018. Rev. Saberes, v.7, n.1.

19. Carvalho, CA; Pinho, JRO; Garcia, PT. Epidemiologia: conceitos e aplicabilidade no Sistema Único de Saúde. 2017. São Luís: Edufma, 24-30. 